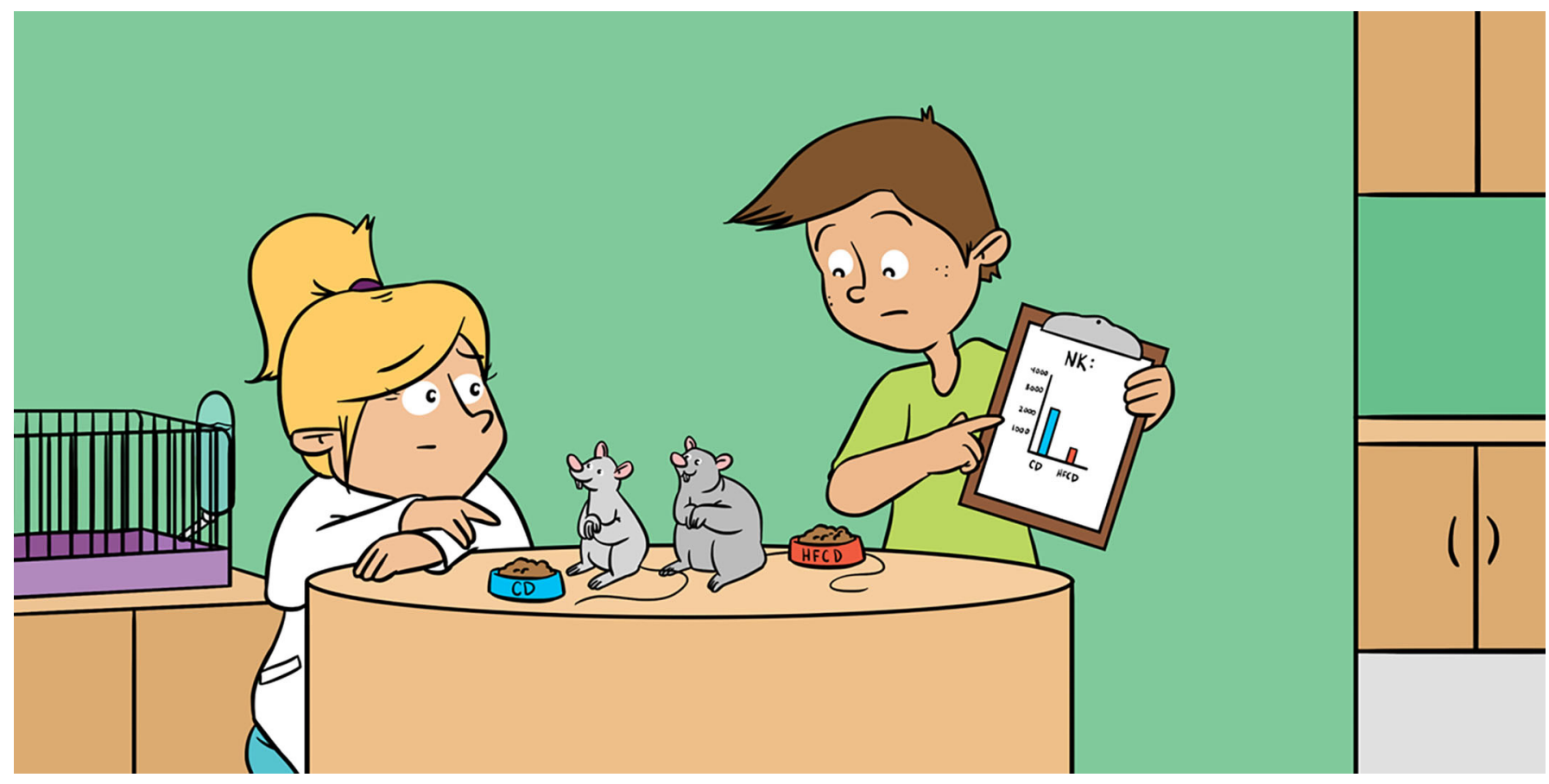

\title{
EATING HEALTHY MIGHT HELP THE IMMUNE SYSTEM FIGHT CANCER
}

\section{Marvin Huynhle ${ }^{1}$ and Kawaljit Kaur ${ }^{2 *}$}

${ }^{1}$ Division of Developmental Stem Cell Biology, Beckman Research Institute at City of Hope, Duarte, CA, United States

${ }^{2}$ Division of Oral Biology and Medicine, The Jane and Jerry Weintraub Center for Reconstructive Biotechnology, University of California, Los Angeles, Los Angeles, CA, United States

\section{YOUNG REVIEWERS:}

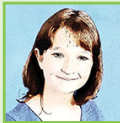

ANNA

AGE: 11

ANOOHYA

AGE: 15
Obesity has been known for years to be a major health problem. Rates of obesity have been steadily increasing all over the world. Many factors, including healthy eating habits and exercise, play important roles in controlling obesity. In our study, we compared the function of cells of the immune system called natural killer (NK) cells between healthy and obese groups of mice. We found that obese mice have lower numbers of NK cells and that NK cells from obese mice are less functional. Lower NK cell activity is related to a higher risk of infections and cancer in the obese group. This research could show a relationship between what we eat and our ability to defend ourselves against diseases like cancer.

\section{WHAT IS OBESITY?}

Obesity is the term for being extremely overweight. Obese people have too much fat in their bodies. Scientists know that genes can 
Figure 1

Where do immune cells come from? The immune system contains many types of cells, all of which originate from cells called multipotent hematopoietic stem cells, which are found in the bone marrow. As HSCs divide, they develop into the many cell types shown in this diagram. In our research, we were interested in NK cells, which are one of the three kinds of lymphocytes.

\section{IMMUNE SYSTEM}

A system of the body that protects it from dangers, such as bacteria, viruses, etc.

\section{LYMPHOCYTES}

A type of white blood cell involved in defending the body

\section{NATURAL KILLER}

\section{CELLS}

A type of white blood cell that attacks cancer cells or cells infected by a virus.

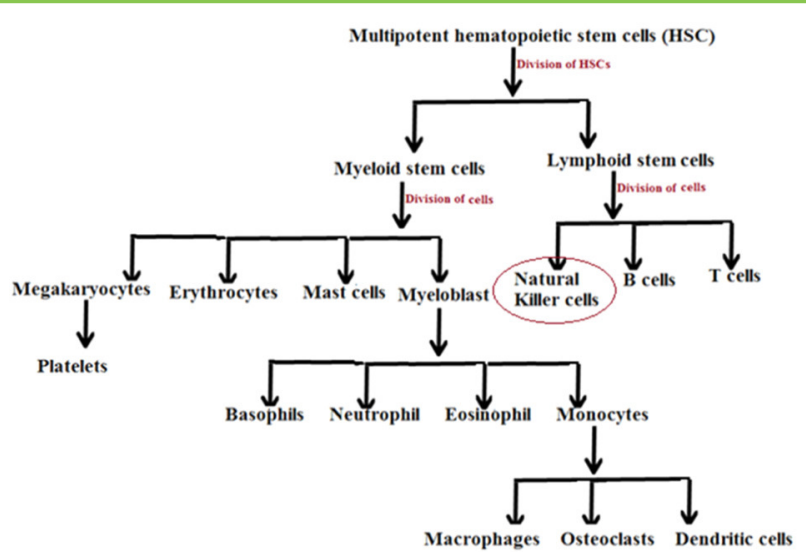

Figure 1

contribute to a person's likelihood of becoming obese, but other things, like lack of exercise and eating a high-fat diet, can also contribute to obesity. The number of obese people in the world is steadily increasing, and obesity is now treated as a disease. We know that obesity causes many health issues. For example, obesity can cause heart problems, because the excess weight makes the heart work too hard, so it gets tired sooner. When the heart gets too tired and weak, it might stop beating and pumping the blood, which can cause death. cardiac arrest or heart failure While we know obesity affects the heart, we do not know everything that it does to other parts of our body. Obese people have also been found to have a higher risk of cancer. Increased risk of cancer could be related to a decreased ability of the immune system to protect us from cancerous cells. Therefore, we decided to study cells of the immune system, to see if they are somehow different in healthy mice than in obese mice.

\section{WHAT IS THE IMMUNE SYSTEM?}

The immune system is extremely important to keep us healthy. It helps defend against infections and diseases caused by bacteria and viruses, and it is also believed to help defend us against cancer. Since we depend on the immune system so much, it makes sense to keep it working at its best. The immune system needs several different kinds of cells to successfully defend our bodies. Figure 1 shows a list of the many kinds of immune cells the body uses to defend itself. All immune cells originate from cells called hematopoietic stem cells, which are found in the bone marrow. All of these immune cells are important, but our study focused on one type of cells, called lymphocytes.

You may ask, "What are lymphocytes?" Lymphocytes can be divided into three different types: T cells, B cells, and natural killer cells (Figure 1). Lymphocytes can remember what they attack. These memories allow the immune system to respond faster the next time they see the same threat. Faster responses mean we get sick less. Did you ever 
Figure 2

Healthy vs. unhealthy natural killer cells. When NK cells are healthy and strong, they can attack cancer cells, killing those cells and causing the cancer to grow more slowly. When NK cells are unhealthy and weak, they cannot kill cancer cells as easily and the cancer can spread.

\section{PERFORIN}

A protein made by immune system cells that create holes in membranes.

\section{PROTEASES}

A type of protein that assists in breaking down other proteins.

\section{NK cells attack cancer cells}
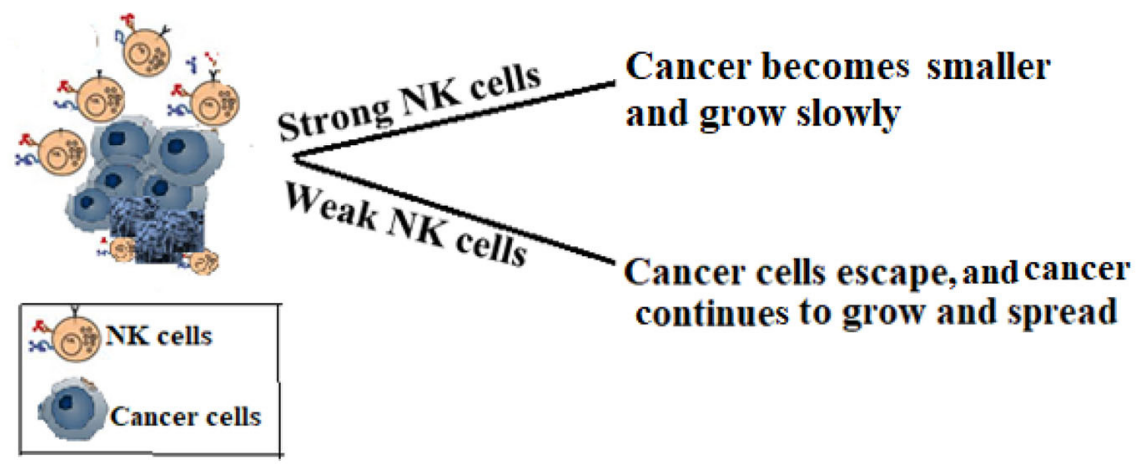

Figure 2

have the chickenpox? If so, you may have had lots of spots on your skin and felt sick for a long time. While you were sick, your immune system was fighting the chickenpox virus. During the fight, your lymphocytes attacked the virus and developed memory for it. After you got better, the memory lymphocytes could recognize the same virus if you came in contact with it again, and destroy it before spots could appear on your skin. Lymphocytes are good for attacking viruses, but not all of them are useful for attacking cancer cells. Natural killer (NK) cells are needed to fight cancer cells [1-3]. Since we were interested in why obese people are more susceptible to cancer, we decided to study the NK cells in both healthy and obese mice.

\section{HAVE NEVER HEARD OF NK CELLS!}

Not many people have heard of NK cells! NK cells were discovered in the early 1980's for their role in killing cancer cells. NK cells only make up $5-10 \%$ of all your white blood cells. But even though there are so few of them, they are still very important. NK cells use two main molecular tools to protect your body: perforins and proteases. Perforins are used to punch holes in the outside walls of cancer cells. The holes allow proteases to invade the cancer cells. Once inside, the proteases attack and break down important cell parts that the cancer needs to spread and survive. If cancer is not able to spread and renew itself, it is much less dangerous. To successfully fight cancer cells, NK cells need to be healthy and fully functional (Figure 2).

\section{OBESE MICE HAVE FEWER, LESS ACTIVE NK CELLS}

To see if diet could affect the number of NK cells, we fed mice with either a high fat-calorie diet (HFCD) or a control, healthy diet (CD). In 4-5 weeks, mice fed HFCD gained 2-3 times more weight compared to mice fed CD. Using flow cytometric analysis, we counted the 
Figure 3

Obese mice have fewer and less active NK cells.

(A) NK cells were removed from the blood of mice and were counted. Mice fed with a high fat-calorie diet (HFCD) had fewer NK cells than mice fed a healthy control diet (CD). (B) NK cells were purified from spleen cells and used as effector cells to target cancer cells. NK cells from mice fed with $C D$ killed $\sim 95 \%$ of the cancer cells, while NK cells from mice fed HFCD killed only $40-50 \%$ of the cancer cells.
A

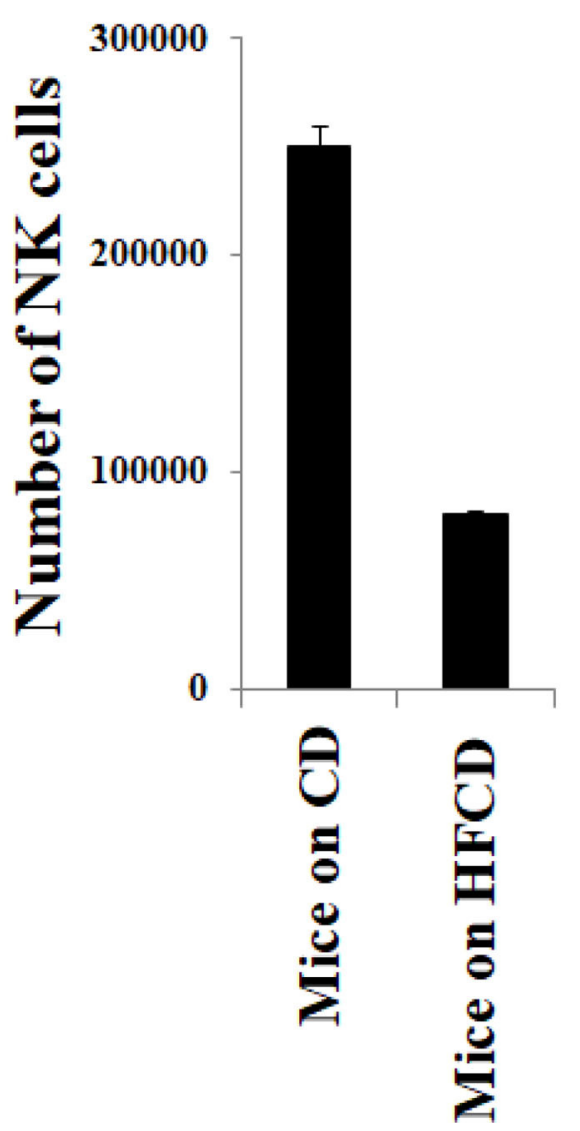

B

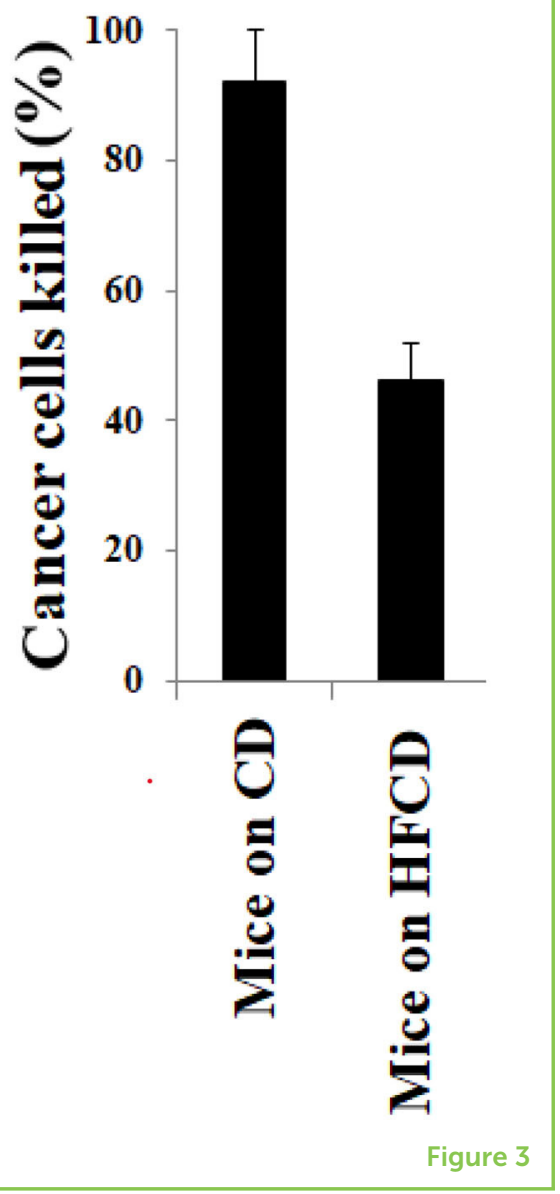

number of NK cells in both obese HFCD mice and CD mice and found that there were fewer NK cells in obese mice (Figure 3A) [4, 5].

To see whether the NK cells from healthy and obese mice could kill cancer cells, we ran cytotoxicity assay in which NK cells are effector cells and tumor cells are targets. We found that NK cells from obese mice were less capable of killing cancer cells (Figure 3B). We think this means that, if the obese mice had cancer, the cancer could spread very easily because the NK cells of those mice are weaker and would not be able to destroy the cancer cells [4]. Although this finding still needs to be confirmed in humans, the results obtained from mice suggest that obese people might also have a smaller number of NK cells and that those NK cells might be less functional than NK cells from non-obese people. This could help explain why obese people have a higher risk of getting cancer compared to healthy people.

\section{PUTTING IT ALL TOGETHER}

The immune system is important. We use it every day for everything from fighting off infections that cause the sniffles up to more serious 
things, like protecting us from cancer. So, it is in our best interest to keep the immune system in great shape. When our bodies get out of shape and become obese, our natural killer cells may show signs of being out of shape, too. In obese mice, there are fewer NK cells and those cells do not do their job of defending mice very well. If these findings hold true in humans, this could make obese humans more vulnerable to cancer, perhaps making it easier for the cancer to spread from one organ to another. It is possible that simply eating a little less fat every day and keeping your body a little healthier may be enough to help your NK cells fight off your body's enemies-even something as dangerous as cancer.

\section{REFERENCES}

1. Kaur, K., Nanut, M. P., Ko, M. W., Safaie, T., Kos, J., and Jewett, A. 2018. Natural killer cells target and differentiate cancer stem-like cells/undifferentiated tumors: strategies to optimize their growth and expansion for effective cancer immunotherapy. Curr. Opin. Immunol. 51:170-80. doi: 10.1016/ j.coi. 2018.03.022

2. Kaur, K., Topchyan, P., Kozlowska, A. K., Ohanian, N., Chiang, J., Maung, P. O., et al. 2018. Super-charged NK cells inhibit growth and progression of stem-like/poorly differentiated oral tumors in vivo in humanized BLT mice; effect on tumor differentiation and response to chemotherapeutic drugs. Oncoimmunology 7:e1426518. doi: 10.1080/2162402X.2018.1426518

3. Kaur, K., Cook, J., Park, S. H., Topchyan, P., Kozlowska, A., Ohanian, N., et al. 2017. Novel strategy to expand super-charged NK cells with significant potential to lyse and differentiate cancer stem cells: differences in NK expansion and function between healthy and cancer patients. Front. Immunol. 8:297. doi: 10.3389/fimmu.2017.00297

4. Kaur, K., Chang, H. H., Topchyan, P., Cook, J. M., Barkhordarian, A., Eibl, G., et al. 2018. Deficiencies in natural killer cell numbers, expansion, and function at the pre-neoplastic stage of pancreatic cancer by KRAS mutation in the pancreas of obese mice. Front. Immunol. 9:1229. doi: 10.3389/fimmu.2018.01229

5. Kaur, K., Chang, H. H., Cook, J., Eibl, G., and Jewett, A. 2017. Suppression of gingival NK cells in precancerous and cancerous stages of pancreatic cancer in KC and BLT-humanized mice. Front Immunol. 8:1606. doi: 10.3389/ fimmu.2017.01606

SUBMITTED: 26 April 2020; ACCEPTED: 17 November 2020; PUBLISHED ONLINE: 11 December 2020.

EDITED BY: Rossana De Lorenzi, Associazione Adamas Scienza, Italy

CITATION: Huynhle M and Kaur K (2020) Eating Healthy Might Help the Immune System Fight Cancer. Front. Young Minds 8:415743. doi: 10.3389/frym.2020.415743

CONFLICT OF INTEREST: The authors declare that the research was conducted in the absence of any commercial or financial relationships that could be construed as a potential conflict of interest. 


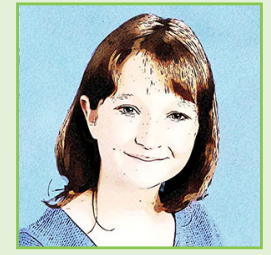

COPYRIGHT () 2020 Huynhle and Kaur. This is an open-access article distributed under the terms of the Creative Commons Attribution License (CC BY). The use, distribution or reproduction in other forums is permitted, provided the original author(s) and the copyright owner(s) are credited and that the original publication in this journal is cited, in accordance with accepted academic practice. No use, distribution or reproduction is permitted which does not comply with these terms.

\section{YOUNG REVIEWERS}

\section{ANNA, AGE: 11}

My name is Anna. I love math and science. My favorite thing to do is read. My favorite sport is taekwondo. My favorite food is sushi. If I were an animal, I would be a cat. I want to live by the quote, "I do not regret the things I have done. I regret the things I did not do when I had the chance."

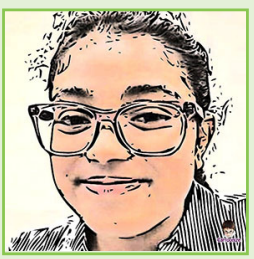

\section{ANOOHYA, AGE: 15}

I enjoy photography, reading, and learning! My areas of interest in STEM include mathematics (competitive), physics, programming (mostly Python and HTML), human biology, and neuroscience.

\section{AUTHORS}

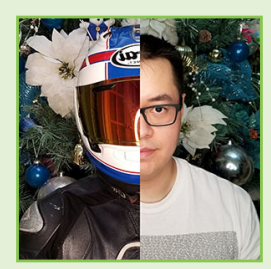

\section{MARVIN HUYNHLE}

Marvin Huynhle is a professor in human anatomy and physiology. He is curious about the immune system and the different things that cause problems with it. His research examined on effects of high-fat diets in fruit flies and brain cancer in humans. His free time involves riding his motorcycle, traveling, and attempting to cook.

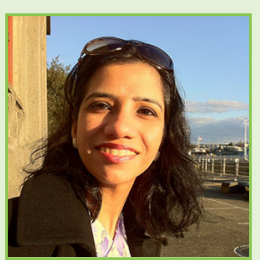

\section{KAWALJIT KAUR}

Dr. Kaur graduated with her Master's degree (M.S.) and a Doctor of Philosophy (Ph.D.) in Oral Biology and Oral Medicine from the University of California, School of Dentistry, Los Angeles in 2015 and 2017, respectively, after which she joined UCLA as a project scientist. She is one of the directors of cure cancer now foundation and has membership in American dental association, International dental association, Indian dental association. Dr. Kaur has given more than 120 invited presentations and has published more than 26 articles in high impact journals. Her work is concentrated on dentistry and cancer cell-based immunotherapy. During $\mathrm{Ph} . \mathrm{D}$. her research project was to investigate the role of Bis-phosphonates in ONJ and allogeneic and autologous NK cell immunotherapies using the humanized BLT mice pancreatic as well as oral cancer models. NK cell immunotherapies were studied as combinational therapy with chemotherapeutic agents and probiotic bacteria. *drkawalmanneg.ucla.edu; *drkawalmann@gmail.com 